\title{
Comparative Study of Vector Control of Induction Motor by Using PI Controller and Fuzzy Controller
}

\author{
Kailash Chandra \\ M.Tech Student, Power Electronics \& \\ Drives \\ DIT University \\ Dehradun, UK, India \\ Email: kailashpurohit100@gmail.com
}

\author{
Prashant Kushwaha \\ Assistant Professor, \\ Department of Electrical Engineering \\ RIPMT Haridwar, UK, India \\ Email: \\ prashantkushwaha1992@gmail.com
}

\author{
Sachin sati \\ M.Tech Student, \\ Power system UTU \\ Dehradun, UK, India \\ Email: \\ sati.sachin@gmail.com
}

\begin{abstract}
Induction Motors have wide kind of functions for the reason that of their advantages likes rugged progress, low rate and strong performance. In latest years, various sides are investigated concerning controlling induction motor. In prior yr's scalar control is use for controlling purpose it is also referred to as $\mathrm{V} / \mathrm{F}$ control. It is vitally easy procedure but the foremost hazards of this procedure are terrible dynamic performance and likewise it takes extra time to come in steady position. After this system vector control is used. Vector control process is more intricate as evaluate to scalar control. The VCIM power includes the decoupling of stator current factor which produces flux and torque of induction motor. It has servable advantages like excellent transient and dynamic performance. However it has some risks like massive ripple in torque within the time of beginning of IM. On this paper, an induction motor (IM) velocity control utilizing, PI controller system and vector control with fuzzy good judgment has been simulated and developed. The comparative be trained of VCIM with fuzzy logic and VCIM with PI is done on MATLAB/SIMULINK program. Results show the effectiveness of vector control with fuzzy logic controller over natural PI established vector control process.
\end{abstract}

Index Terms - component; Induction motor, vector control, mathematic modeling, Fuzzy logic controller.

\section{INTRODUCTION}

Induction motors are used in many industrial functions due less maintenance, robustness and simple building. Maximum torque and effectively may also be got by way of correct controlling of induction machine. In today's years, the control of the induction motor vigor is an energetic is taught self-discipline for engineers. Most of the time, the control and estimation of ac machines is difficult within the compression of dc drives, and this predicament develop if high performance is demanded. In $\mathrm{V} / \mathrm{F}$ manipulate required suggestions sign but because of presence of harmonic quandary comes within the processing of suggestions signal. Probably the most long-established approach for controlling of induction motor use in industries is vector control or field oriented control. There are virtually two original approaches of vector control. One called the direct or suggestions approach, and the other, the oblique or feed ahead system. Indirect vector controlled (IVC) induction motor (IM) drives utilized in excessive efficiency programs could be very modern day in industrial purposes consequently of their relative convenient configuration, as in evaluation with the direct approach which requires flux and torque estimator. The main benefits of oblique vector manipulate are the decoupling of torque and flux without difficulty. Vector control is often referred to as decoupling, orthogonal or Tran's vector manage. Vector manipulate provide more accurate outcome as compare to scalar manage due to this advantages it become commonplace control of ac machines [1]. Conventionally PI controller used for controlling motive and it offers good outcome. But in some software like ac drives it's now not provide fascinating effect. So we required an enhance system akin to fuzzy good judgment for reaching desirable effect. On this paper comparative be taught between the fuzzy based vector control and traditional vector control is finished

\section{Vector Control Or Field Oriented Control: Selecting a Template}

The other title of Vector control is Field-oriented control (FOC), is a frequency control system where the stator currents of a 3-section AC laptop are divided as two 
orthogonal add-ons that may be visualized with a vector. One factor defines the magnetic flux of the laptop, the opposite the torque. The manipulate approach of the force calculates from the flux and torque references given by way of utilizing the force's pace manage the corresponding present facet references. Conventionally used proportional-integral (PI) controllers for evaluating measured current with their reference values. In keeping with PI controller output transistor switch and the stator voltage of motor produce in accordance transistor switching. Vector manipulate induction motor can be manage like individually excited DC motor. Vector manipulate is suitable for both the synchronous and induction desktop drives. In DC machine, subject flux is perpendicular (Ninety Degree) to the armature flux. These two fluxes don?t produces any interaction with each other. By using and adjusting the subject current will manage the DC commutator flux, and the torque might also be manage severally of flux by means that of utilizing adjusting the armature current. The development of AC computing device just isn't simple like DC computing device, in AC computing device both stator and rotor flux intersect each other and flux linking of stator and rotor exchange in line with jogging situation we're ready to receive DC laptop like efficiency in protecting a orthogonal and consistent orientation between the armature fields and area. In $A C$ devices through dimensioning the current of the stator with admire to the flux of the rotor to be competent to acquire independently managed torque and flux [3]. Vector manipulate is suitable to each synchronous and induction motor drives. The cage of induction motor powered with the vector manipulate offers a excessive stage of dynamics efficiency and the closed-loop manage provide fast and correct response of approach. Induction Motor drives are being utilized in the numbers of many procedure and commercial manipulate functions which are requires the immoderate performances [4]. In excessive performance pressure approaches, the motor velocity ought to closely accommodates a specific reference mechanical phenomenon prevailing any load disturbances, parameter variants, and mannequin uncertainties. In order to accumulate excessive performance, area-oriented control of induction motor (IM) drive is utilized. However, the controller design of this type of procedure performs a imperative perform in strategy effectively. Due to parameter exchange decoupling traits of vector controlled IM are associate affected. So the vector management is additionally referred to as associate freelance or decoupled management.

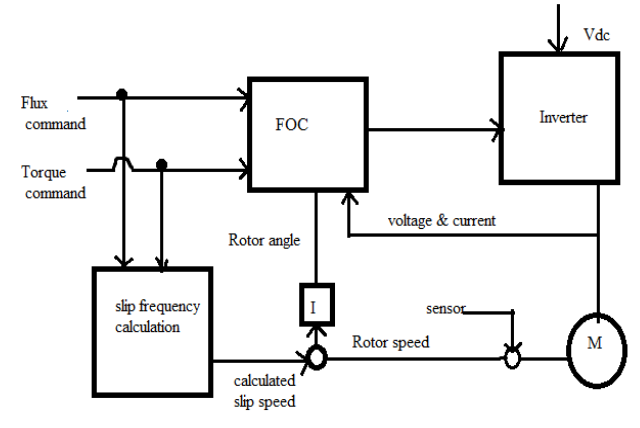

Fig: 1 Field Oriented Control

\section{INDUCTION MOTOR MODELLING:}

With the intention to lower the complexity of the modeling the 3 section parts reborn to two section method. The modified voltage equations (1) for the rotor and mechanical device on the synchronously rotating reference body ar as follows:-

$$
\begin{gathered}
\mathrm{Vds}=\mathrm{RsIds}+\mathrm{D} \Psi \mathrm{ds} \\
\mathrm{Vqs}=\mathrm{RsIqs}+\mathrm{D} \Psi \mathrm{qs} \\
\mathrm{Vdr}=\mathrm{RrIdr}+\mathrm{wr} \Psi \mathrm{dr}+\mathrm{D} \Psi \mathrm{dr} \\
\mathrm{Vqr}=\mathrm{RrIqr}-\mathrm{wr} \Psi \mathrm{qr}+\mathrm{D} \Psi \mathrm{qr} \\
\Psi \mathrm{ds}=\int(\mathrm{Hds}-\text { RsIds }) \\
\Psi \mathrm{qs}=\int(\text { Hqs }- \text { RsIqs }) \\
\mathrm{ET}=\mathrm{p} \Psi \mathrm{dsIqs}-\Psi \mathrm{qs} \text { Ids }
\end{gathered}
$$

Where, $\mathrm{Vdr}=$ rotor $\mathrm{d}$-axis voltage, $\mathrm{Vqs}=$ stator $\mathrm{q}$-axis voltage, $\mathrm{Vqr}=$ rotor $\mathrm{q}$-axis voltage, $\Psi \mathrm{qs}=$ stator q-axis flux, $\mathrm{Vds}=$ stator $\mathrm{d}$-axis voltage, $\Psi \mathrm{ds}=$ stator $\mathrm{d}$-axis flux, $\mathrm{ET}=$ Electromagnetic torque.

\section{PI CONTROLLER DESIGN}

The normal PI controller output is given along with the help of the below equation:

$$
U=k e(t)+k \int e(t) \cdot d t
$$

Where, $\mathrm{e}=$ error (difference between actual speed and reference speed), $\mathrm{k}=$ proportional gain, $\mathrm{k}=$ Integral gain.

\section{FUZZY LOGIC CONTROLLER:}

Fuzzy logic controller consist three parts.

- Fuzzification

- Inference

- Defuzzification

- In fuzzification covert crisp value in fuzzy set that is lie between $(0,1)$. Inside the fuzzification step the error and modification in error signals area unit normalized to values that belong between -1 to one. The triangular and trapezoidal membership operate makes the calculations easier and controller to be straightforward [2]. 
- In inference engine all rule are utilized to the approach and manage output in step with requirement.

- In defuzzification fuzzy set convert into crisp value.

Fuzzy logic control (FLC) is a manipulate calculation taking into consideration an etymological control methodology which tries to account the human's finding out about methods to control a procedure without requiring a numerical model [9]. Normal block diagram of FLC proven in fig 2 .

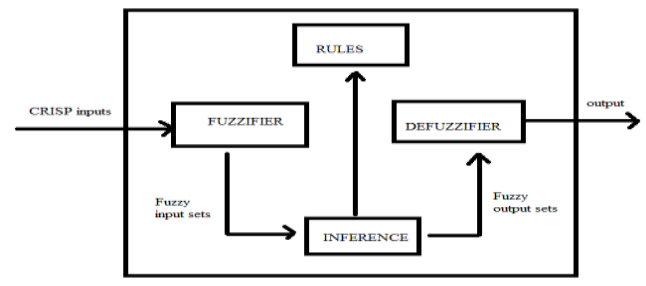

Fig 2: Block diagram of fuzzy logic controller

\section{FLCDESIGN:}

Membership functions required for designing of a fuzzy common sense controller. The membership services should be picked such that they cover the entire universe of talk. Membership functions should be overlapping every different. This is executed in order to restrict any type of brokenness related to the minor changes in the inputs. For better manipulate, the membership perform close the zero areas must be made tight. Broader member operate works far from the zero areas offers speedier response to the system. Therefore, the membership function will have to be adjusted as standards are. After settling on compatible membership capabilities, a rule base must be made. It comprises exceptional Fuzzy IfThen chooses that entirely painting the behavior of the structure. These rules all that so much takes after the human standpoint, on this method giving electronic pondering to the approach [5, 6, 7and 8].

\section{PLOT OF MEMBERSHIP FUNCTION}

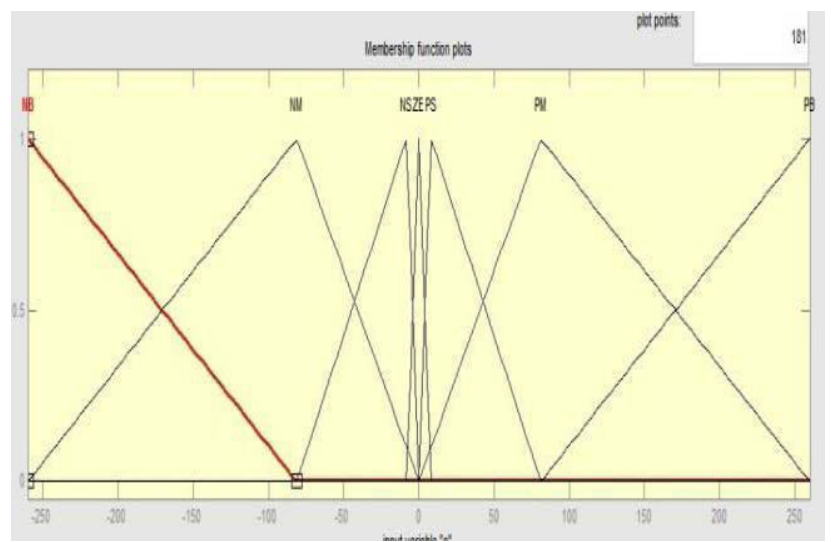

\section{INPUT VARIABLE ERROR \& CHANGE IN ERROR}

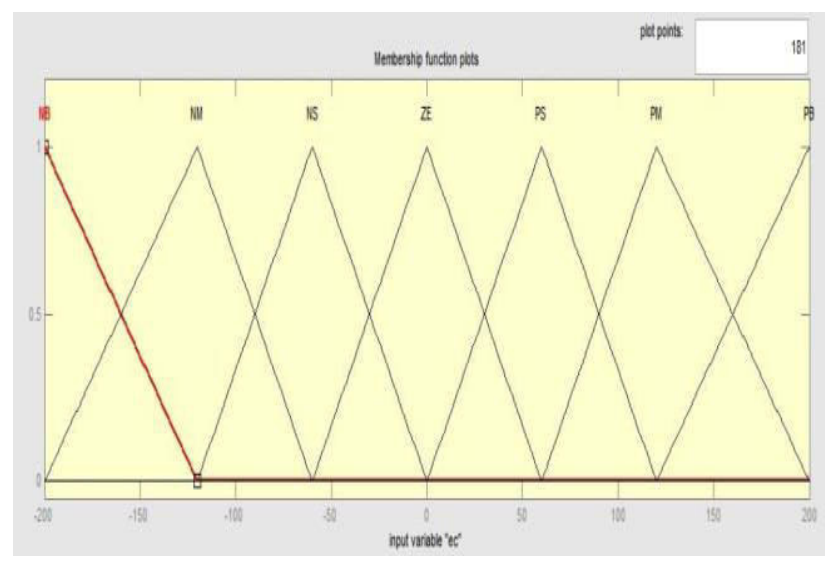

OUTPUT VARIABLE
FLC RULE BASE TABLE

\begin{tabular}{|l|l|l|l|l|l|l|l|}
\hline e/ & N & N & N & Z & P & P & P \\
de & B & M & S & E & S & M & B \\
\hline N & N & N & N & N & N & N & Z \\
B & B & B & M & M & S & S & E \\
\hline N & N & N & N & N & N & Z & P \\
M & L & M & M & S & S & E & S \\
\hline N & N & N & N & N & Z & P & P \\
S & M & M & S & S & E & S & S \\
\hline Z & N & N & N & Z & P & P & P \\
E & M & S & S & E & S & S & M \\
\hline P & N & N & Z & P & P & P & P \\
S & S & S & E & S & S & M & M \\
\hline P & N & Z & P & P & P & P & P \\
M & S & E & S & S & M & M & L \\
\hline P & Z & P & P & P & P & P & P \\
B & E & S & S & M & M & B & B \\
\hline
\end{tabular}

VII. SIMULATION RESULTS:

A. Circuit Description:

The induction motor is hooked up by way of a presentmanaged PWM inverter which consist block of common Bridge. The motor drives having a mechanical load is characterised by inertia $\mathrm{J}$, friction coefficient $\mathrm{B}$, and cargo torsion metallic element. For velocity manage loop makes use of a PI and Fuzzy common sense controller. Q Axis present (iq*) manage motor torque and motor flux is control by means of $\mathrm{d}$ axis present (id*). Identification* and $\mathrm{iq}^{*}$ convert into current references $\mathrm{ia}^{*}, \mathrm{ib}^{*}$, and $\mathrm{ic}^{*}$ with the aid of utilizing block dq-abc for the regulating of present. Current and Voltage dimension blocks are used to for sign visualization motive. Motor present, pace, and torque alerts are to be had at the output of the 'Asynchronous computer' block supply sign of motor torque, present and pace. 
For papers to be published in translation journals, please give the English citation initial, followed by original and genuine foreign-language citation [6].
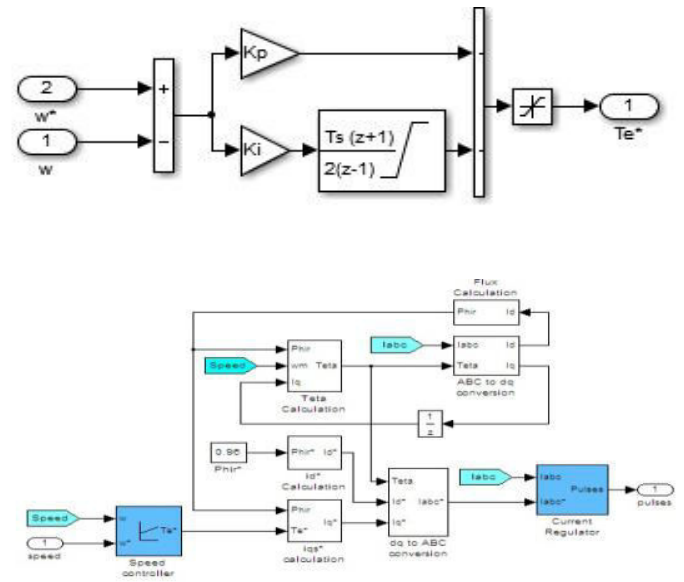

Fig 3 PI based vector control

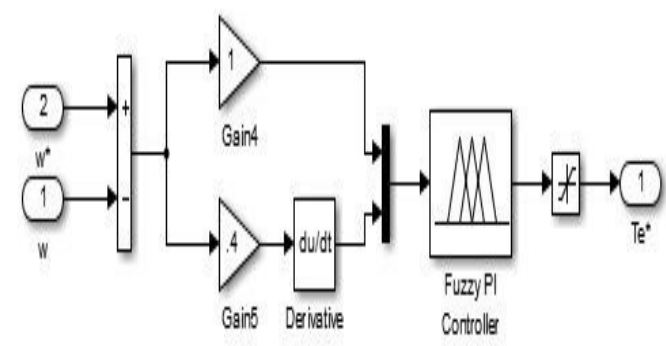

Fig 4 Fuzzy based vector control

B. At no Load:

The results shows that, When a pace reference step from zero to at least one hundred twenty rpm is utilized at $t=0$ $\mathrm{sec}$, the speed set point doesn't go immediately at one hundred twenty rpm nevertheless follows the acceleration ramp as tested in fig 3 and fig 4 . Motor reached at stable state at $2.5 \mathrm{sec}$ in conventional PI base vector manipulate but in fuzzy established vector manage motor reached steady state in $1.5 \mathrm{sec}$.

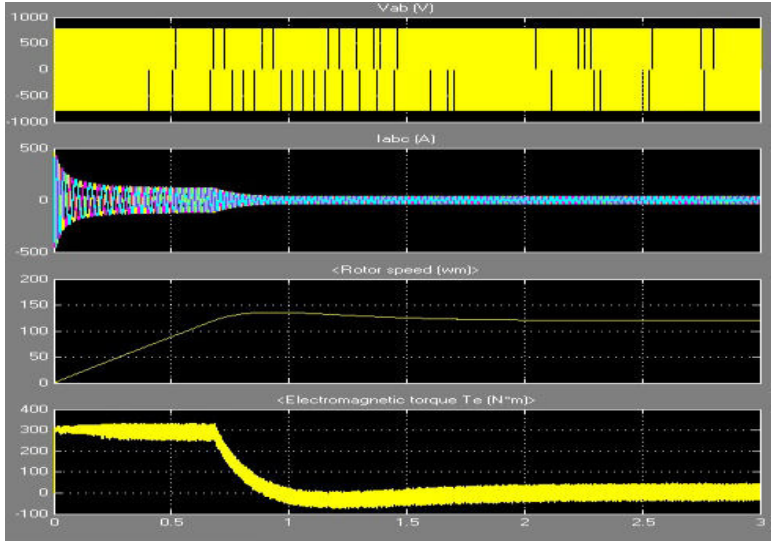

Fig 5: PI base vector control

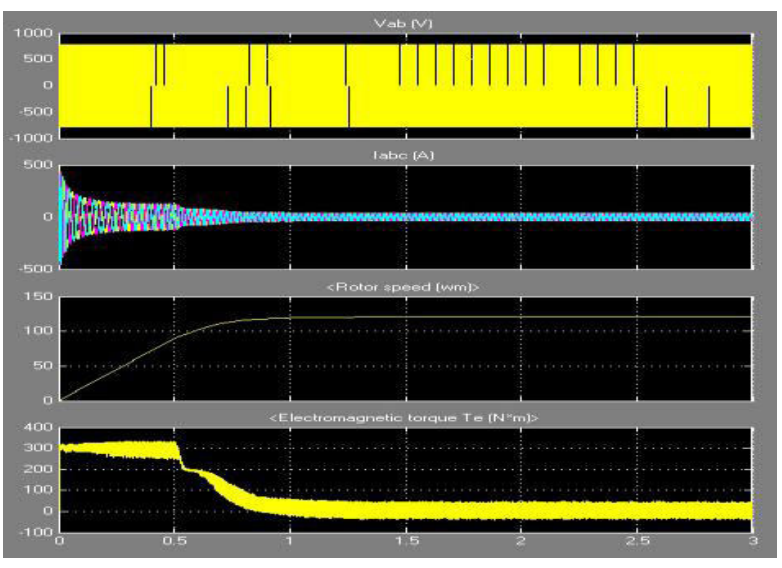

Fig 6: Fuzzy base vector control

AT Load

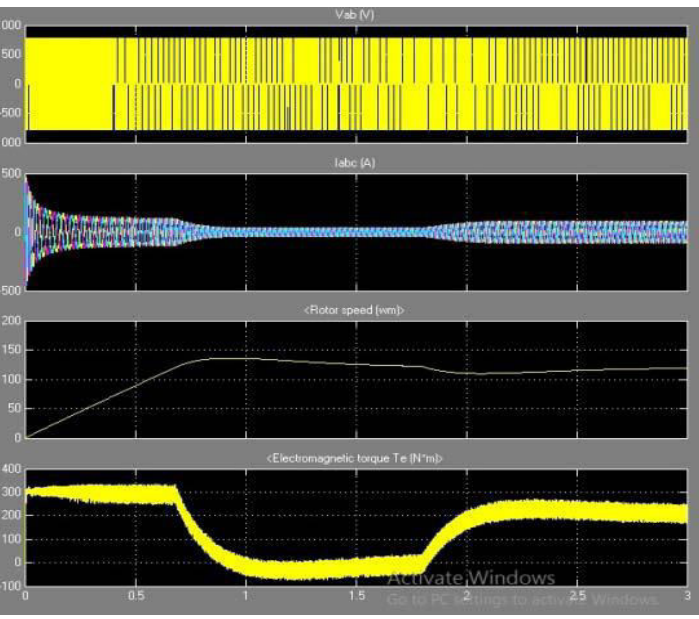

Fig 7: PI base vector control 


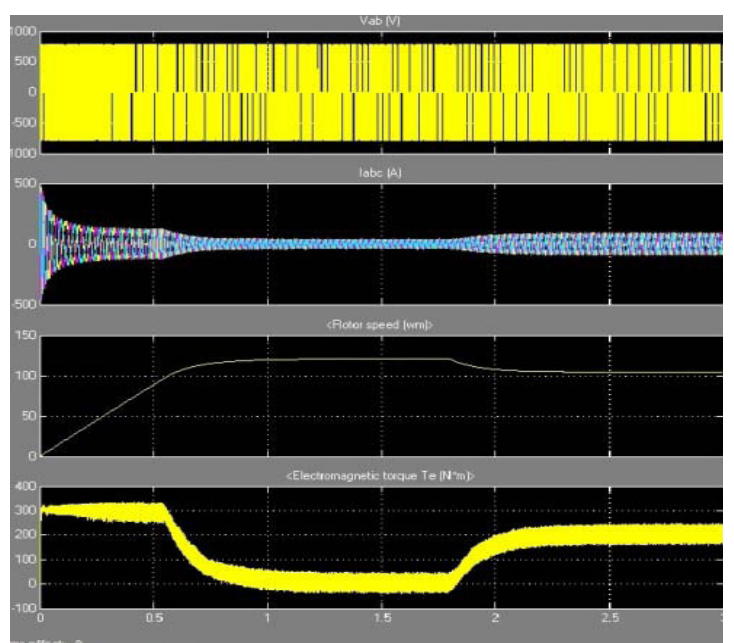

Fig 8: Fuzzy base vector control

\section{CONCLUSION}

On this paper we determined that standard PI has additional sinking time than fuzzy controller, so fuzzy controller makes the procedure turbo. The highest overshoot moreover within the normal PI controller is found larger than fuzzy controller. Once more the variant within the strategy parameters so of load disturbances is additionally a lot of less with fuzzy controller, which proves that the fuzzy controller is higher than the traditional PI controller. So it is typically terminated that the fuzzy controller improves the procedure performance and is best appropriate to excessive potency drives.

\section{REFERENCES}

[1] Bose, Bimal K. "MPE and AC Drives" New Delhi, Prentice- Hall, 2002.

[2] Novotny, "Selecting the flux reference for induction machine drives in the field weakening region," IEEE Trans. Ind. Applicat., vol. 28, pp. 1353-1358, Nov./Dec. 1992.

[3] J. W. Finch, "Application of estimation technique in vector controlled induction motor drives," IEE Conference Proceeding, London, July 1990 , pp. 358-363.

[4] Lee Zihong, "Methods for improving performance of PI type fuzzy logic controller," IEEE trans. on fuzzy systems, vol.1, no. 4, Nov 1993.

[5] Masiala M., Salmon J., "Fuzzy self tuning speed control of an indirect field-oriented control induction motor," IEEE Trans. industry appl., vol. 44 , No. 6 ,Dec 2008.

[6] Mudi R.K. and Pal N. R., "A robust self tuning scheme for PI and PD type fuzzy controllers," IEEE Trans. fuzzy systems, vol. 7, no. 1, Feb 1999.

[7] Sun J, P. Su, and L. Li, "Application of self-adjusting fuzzy controller in a vector- controlled induction motor drive," in Proc. 3rd IEEE Int. Conf. Power Electron. Motion Control, Aug. 15-18, 2000, vol. 3.

[8] Bhadra S. N., D. Kastha, and S .Banerjee, Wind Electrical Systems, Oxford University Press, New

[9] Gilberto C D Souse, Bimal K Bose, "A fuzzy set theory based control of phase controlled converter DC motor drive", IEEE Transactions On Power Delivery, vol. 14, no. 2, july 2011. 